\title{
Effect of long-term industrial waste effluent pollution on soil enzyme activities and bacterial community composition
}

\author{
Gangavarapu Subrahmanyam • Ju-Pei Shen • \\ Yu-Rong Liu • Gattupalli Archana • Li-Mei Zhang
}

Received: 7 July 2015 / Accepted: 6 January 2016 / Published online: 23 January 2016

(C) Springer International Publishing Switzerland 2016

\begin{abstract}
Although numerous studies have addressed the influence of exogenous pollutants on microorganisms, the effect of long-term industrial waste effluent (IWE) pollution on the activity and diversity of soil bacteria was still unclear. Three soil samples characterized as uncontaminated (R1), moderately contaminated (R2), and highly contaminated (R3) receiving mixed organic and heavy metal pollutants for more than 20 years through IWE were collected along the Mahi River basin, Gujarat, western India. Basal soil respiration and in situ enzyme activities indicated an apparent deleterious effect of IWE on microbial activity and soil function. Community composition profiling of soil bacteria using 16S rRNA gene amplification and denaturing gradient gel electrophoresis (DGGE) method
\end{abstract}

Electronic supplementary material The online version of this article (doi:10.1007/s10661-016-5099-4) contains supplementary material, which is available to authorized users.

G. Subrahmanyam · J.-P. Shen · Y.-R. Liu •

L.-M. Zhang $(\bowtie)$

Research Center for Eco-Environmental Sciences, Chinese

Academy of Sciences, 18 Shuangqing Road, Beijing 100085,

China

e-mail: zhanglm@rcees.ac.cn

G. Subrahmanyam · G. Archana

Department of Microbiology and Biotechnology Centre, The

Maharaja Sayajirao University of Baroda, Vadodara 390002, India

Present Address:

G. Subrahmanyam

Central Muga Eri Research and Training Institute,

Lahdoigarh, Jorhat 785700 Assam, India indicated an apparent bacterial community shift in the IWE-affected soils. Cloning and sequencing of DGGE bands revealed that the dominated bacterial phyla in polluted soil were affiliated with Firmicutes, Acidobacteria, and Actinobacteria, indicating that these bacterial phyla may have a high tolerance to pollutants. We suggested that specific bacterial phyla along with soil enzyme activities could be used as relevant biological indicators for longterm pollution assessment on soil quality.

Keywords Industrial waste effluent · Long-term pollution · Soil enzyme activity · 16S rRNA gene · Denaturing gradient gel electrophoresis · Biological indicators

\section{Introduction}

Soil contamination with industrial waste is considered to be a serious environmental issue. Soil microbial activity and diversity are highly sensitive to soil contamination by organic and inorganic pollutants, including heavy metals (Zhang et al. 2010a, b; Thavamani et al. 2012; Subrahmanyam et al. 2014a). It was found that both short-term and long-term exposures to heavy metals resulted in the reduction of soil microbial activity and diversity (Khan et al. 2007; Sheik et al. 2012). Heavy metals adversely affect the activity and diversity of soil microbial communities associating with elemental cycling (Wang et al. 2007; Subrahmanyam et al. 2014a, c). A significant decrease in bacterial diversity has been observed with increased soil pollution 
(Subrahmanyam et al. 2014c). Therefore, soil microbial activity and community structure are accepted as indicators of overall soil environmental quality (Winding et al. 2005; Igbinosa 2015).

In earlier studies, microbial responses were measured after "fresh" additions of pollutants under short-term incubation period, thus reflecting acute toxicity, rather than long-term chronic toxic effects of pollutants on soil microbes. So that, further field research is required for better understanding of soil microbial dynamics, the relative contributions of specific bacterial phyla to a particular soil function, and the microbial metabolic rates in long-term polluted soils. For example, pollutioninduced bacterial community shift and abundance of Proteobacteria were observed in soils under long-term exposure of heavy metals (Sheik et al. 2012). In another study, the higher percentage of Proteobacteria, Firmicutes, and Actinobacteria were noticed in long-term polluted soils in which hydrocarbon was the main contaminant (Vivas et al. 2008). Pollution-induced bacterial community shifts were observed with organic pollutants such as phenanthrene, fluoranthene, pyrene, benzo(a)pyrene, and herbicides (Tian et al. 2008; Zhang et al. 2014). Studies suggested that the indigenous bacteria are very sensitive to contaminants and respond rapidly to organic pollutants (Tian et al. 2008). In short-term pollution-affected soils, bacterial diversity may be maintained through either natural resistance or dormancy (Jones and Lennon 2010). However, long-term chronic exposure to contamination will have deleterious and unrecoverable effects on the structure and function of the community as the dormancy may not be a useful survival option any longer. Most often polluted sites are exposed to mixed contamination of various metals and organic pollutants (Vivas et al. 2008), and may cause deteriorative influence on microorganisms, while the co-occurrence of organic pollutants with heavy metals and their longterm effect on soil microbial activities have not been systematically investigated. Characterizing the effect of mixed pollutants on soil microorganisms is important for understanding their toxic effects in the environment and for the development of adequate bioremediation strategies.

In our previous study, we found that long-term industrial waste effluent (IWE) pollution resulted in a significant decrease in both soil potential nitrification and diversity of nitrifiers, and that the archaeal $16 \mathrm{~S}$ rRNA gene and functional amo $A$ gene abundance were greatly reduced by IWE pollution (Subrahmanyam et al. 2014c). However, the study just concentrated on the influence of long-term IWE pollution on soil nitrifiers, the knowledge on how the IWE pollution affect the soil enzymes and general bacterial community is hardly known. In this study, the community composition and activity of bacteria in three soils samples which received non-contamination (R1), moderate IWE contamination (R2), and highly IWE contamination (R3) for more than 20 years along Mahi River basin, Gujarat, western India, were investigated using the fingerprint analysis, sequencing technique combined with soil enzyme activities measurement, aiming to explore the response of bacterial community composition and activity to the long-term industrial pollution, and to figure out the dominant and sensitive bacterial phyla in the mixed organic and heavy metal-polluted soils and to propose the potential biological indicators to assess the soil quality.

\section{Materials and methods}

\section{Sampling sites}

Three different sites characterized as uncontaminated (R1), moderately contaminated (R2), and highly contaminated (R3) were chosen along Mahi River basin, sub-humid region, Gujarat, western India (Fig. 1). Geologically, all these three sites have evolved under the same alluvial sedimentary origin, and texturally all these three sites were silty-loam in nature. Pre-polluted soil properties of polluted sites (R2 and R3) were found to be the same as R1. However, due to the long-term industrial waste effluent contamination, the chemical properties of R2 and R3 have changed considerably. Soil samples at R2 and R3 sites have been receiving mixed contamination of organic (primarily organohalogens, polyaromatic hydrocarbons, phenolic and aliphatic compounds) and varying degrees of heavy metal pollutants for more than 20 years through IWE (Labunska et al. 1999; Subrahmanyam et al. 2014c). The uncontaminated soil R1, as a control, was collected from the nearest unpolluted area within the vicinity of the R2 site. Details about the site location, soil sampling, and soil physicochemical properties including heavy metal analysis have been reported in our earlier study (Subrahmanyam et al. 2014c) and also listed in Tables 1 and 2. In all these sites, the landscape is 
Fig. 1 Location map of sampling site. Study sites are shown with red color square boxes

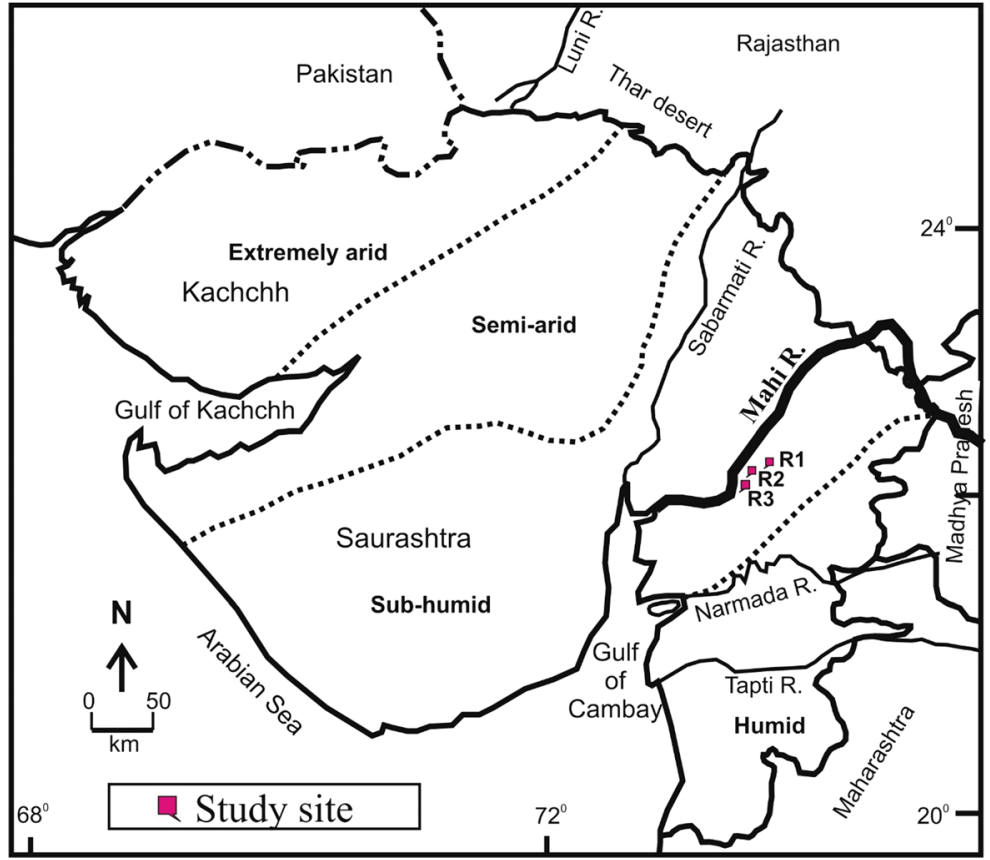

covered with Calotrophis procera, Acasia, Digitaria sp., Brachiaria sp., Datura stramonium, Parthenium sp., Brasssica sp., and Cynodon dactylon.

Ten cores for each sample were mixed, and three replicates were collected for each sampling location at a depth of $0-20 \mathrm{~cm}$. All the samples were placed in autoclaved polyethylene bags and kept on ice during the transportation to the lab. Then, the soil samples were gently crumbled, mixed thoroughly, and passed through a $2.0-\mathrm{mm}$ sieve. Processed soil samples were stored at $4{ }^{\circ} \mathrm{C}$ for analysis of soil characteristics and at $-80{ }^{\circ} \mathrm{C}$ for DNA extraction (Subrahmanyam et al. 2014c).

Determination of soil physiochemical properties

Detailed methodology for soil physiochemical properties of R1, R2, and R3 soils were mentioned in our earlier article (Subrahmanyam et al. 2014c). In brief, soil texture, $\mathrm{pH}$, and organic matter content were estimated by standard protocols as described by Alef and Nannipieri (1995). Total C (TC), total N (TN), and total $\mathrm{S}$ (TS) were estimated by a combustion analyzer (Vario ELIII elemental analyzer, Germany). Soil samples were digested with $\mathrm{HNO}+\mathrm{HCl}(10 \mathrm{ml}, 1: 1 v / v)$ for detecting heavy metals by ICP-OES (PerkinElmer, California, USA). The polycyclic aromatic hydrocarbons (PAHs) in soil samples were extracted according to the USEPA Soxhlet extraction method (US EPA Method 3540C 1996). In brief, $2.5 \mathrm{~g}$ of soil was extracted with acetone-dichloromethane $(1: 1, v / v)$ for $24 \mathrm{~h}$ at $65{ }^{\circ} \mathrm{C}$. Subsequently, the extracts were concentrated to small volumes after addition of sodium sulfate to remove water fraction. The extracts were later analyzed for PAHs through high performance liquid chromatography (HPLC) equipped with UV detector at $254 \mathrm{~nm}$ (Bishnoi et al. 2009). As shown in Table 2, the heavy metals concentrations in polluted soils R2 and R3 were significantly higher than the control soil R1. Furthermore, R2 and R3 soils were heavily contaminated with PAHs such as naphthalene, phenanthrene, acenaphthene, anthracen, pyrene, and fluoranthene. Among six PAHs estimated, the concentrations of naphthalene and phenanthrene were relatively high in R2 and R3 soil samples (Table S1). The total resolved PAHs were found to be 164.2 and $328.8 \mathrm{mg} \mathrm{kg}^{-1}$ soil, in R2 and R3 soils respectively (Table S1).

Soil microbial activity measurements

Basal soil respiration (BSR) was determined by measuring the amount of $\mathrm{CO}_{2}$ evolved during incubation of soil in a closed container (Vance et al. 1987). Soil enzyme 


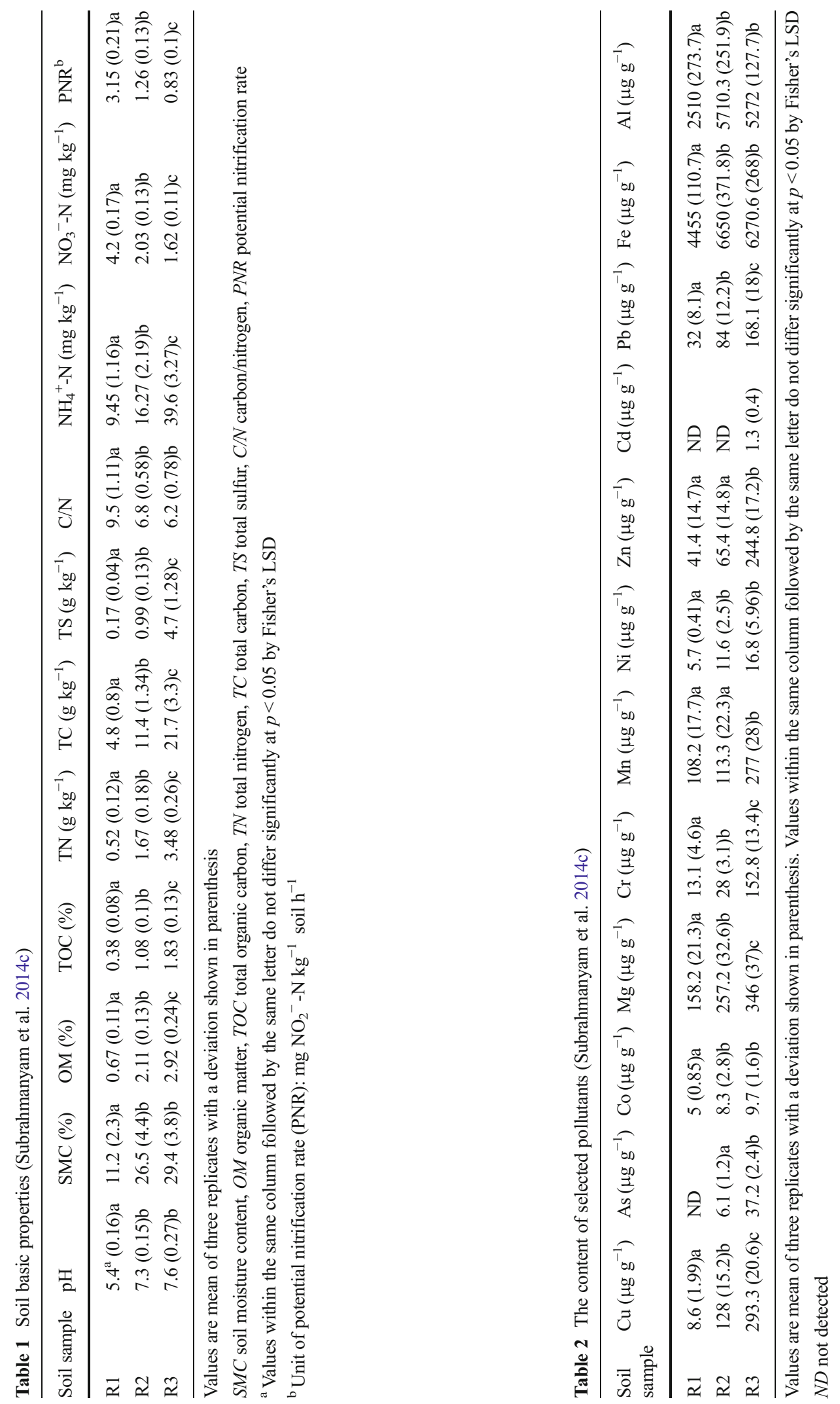


activities, including $\beta$-glucosidase (GSA), alkaline phosphatase (PSA), and protease (PRA) involved in C, $\mathrm{P}$, and $\mathrm{N}$ cycling, were estimated with methods as described previously (Alef and Nannipieri 1995; Subrahmanyam et al. 2011, 2014b). Soil dehydrogenase (DHA) activity was measured by reduction of soluble tetrazolium salt 2,3,5-triphenyltetrazolium chloride, as an artificial electron acceptor to redcolored formazans, extracted and estimated colorimetrically (Alef and Nannipieri 1995).

Soil DNA extraction and 16S rRNA gene amplification

Soil genomic DNA was extracted from $0.5 \mathrm{~g}$ subsamples using Ultra-clean ${ }^{\mathrm{TM}}$ soil DNA isolation kit (MoBio Laboratory, USA) following the manufacturer's protocol. The size of the extracted DNA was checked on a $1 \%$ agarose gel and the purity of DNA was evaluated by spectrophotometry (NanoDrop Technologies, Wilmington, DE, USA). Subsamples of extracted DNA were kept at $-20^{\circ} \mathrm{C}$ for further quantitative and qualitative analysis. Bacterial 16S rRNA genes suitable for diversity profiling of denaturing gradient gel electrophoresis (DGGE) were amplified using primer sets 954f-GC/1369r (Yu and Morrison 2004). Detailed thermal profiles of PCR amplification have been described in previous studies (Yu and Morrison 2004). Briefly, a touchdown thermal cycle strategy consisting of 10 cycles $\left(30 \mathrm{~s}\right.$ at $94{ }^{\circ} \mathrm{C}$, annealing for $30 \mathrm{~s}$ at temperature decreased from 61 to $56{ }^{\circ} \mathrm{C}$ and extension at $72{ }^{\circ} \mathrm{C}$ for $1 \mathrm{~min}$ ) followed the additional 22 cycles (consisting of $30 \mathrm{~s}$ at $94{ }^{\circ} \mathrm{C}, 30 \mathrm{~s}$ at $56{ }^{\circ} \mathrm{C}$, $1 \mathrm{~min}$ at $72^{\circ} \mathrm{C}$ ) and then a final extension for $5 \mathrm{~min}$ at $72{ }^{\circ} \mathrm{C}$ were performed.

\section{DGGE and sequencing analysis}

DGGE was carried out with a DCode Universal Mutation Detection System (Bio-Rad, Germany) as described in our recent study (Subrahmanyam et al. 2011). The obtained PCR products were loaded on $6 \%(w / v)$ acrylamide/bisacrylamide $(37: 1, w / w)$ gels containing a 30 to $60 \%$ linear gradient of formamide and urea (where $100 \%$ denaturing solution contained $40 \%(v / v)$ formamide and $7 \mathrm{M}$ urea). After the electrophoresis, the gels were stained with 1:10,000 SYBR Gold Nucleic Acid Gel Stain (Invitrogen-Molecular Probes, Eugene, OR, USA) according to the manufacturer's instructions and scanned by a GBOX/HR-E-M (Syngene, UK). The gel picture was analyzed using the software "AlphaEase FC" (Alpha Innotech, CA, USA). The experiment was repeated twice to confirm the reproducibility. The dominant bands numbered in the DGGE gel and other bands with the same mobility were excised, cloned, and sequenced. For each DGGE band, five positive clones were selected for sequencing analysis. Sequences were subjected to BLAST analysis in the NCBI GenBank (www.ncbi.nlm.nih.gov) database, and sequence chromatograms were manually edited with DNAStar and DNAMAN version 6.0. Phylogenetic analysis was conducted using MEGA version 5.0. Diversity indices such as Shannon index $(H)$ and Evenness index $(E)$ were measured as described in our earlier articles (Shen et al. 2008; Subrahmanyam et al. 2014c). The range-weighted richness $R r$ index was determined to understand the broader carrying capacity of the soils for microbial groups (Subrahmanyam et al. 2014c).

Statistical analysis

The relationship between soil chemical characteristics and microbial parameters was elucidated by principal components analysis using "CANOCO for Windows," Version 4.5 software. Quantitative differences of all the sample means were conducted with one-way analysis of variance (ANOVA) by Fishers least significant difference test (LSD). In the present study, $p<0.05$ was considered to be statistically significant. All statistical analyses were performed using "SPSS version 15.0" and "SigmaStat version 3.5."

Sequence accession numbers

Nucleotide sequences of bacterial 16S rRNA gene fragments retrieved from this study have been deposited in the GenBank nucleotide sequence database under accession nos. JX504051 to JX504076 (NCBI GenBank, www.ncbi.nlm.nih.gov).

\section{Results}

Soil enzyme activity and respiration measurements

Soil microbial activity as indicated by soil enzymes and BSR was presented in Fig. 2. Soil enzyme activities showed significant variation between soils. Relatively 

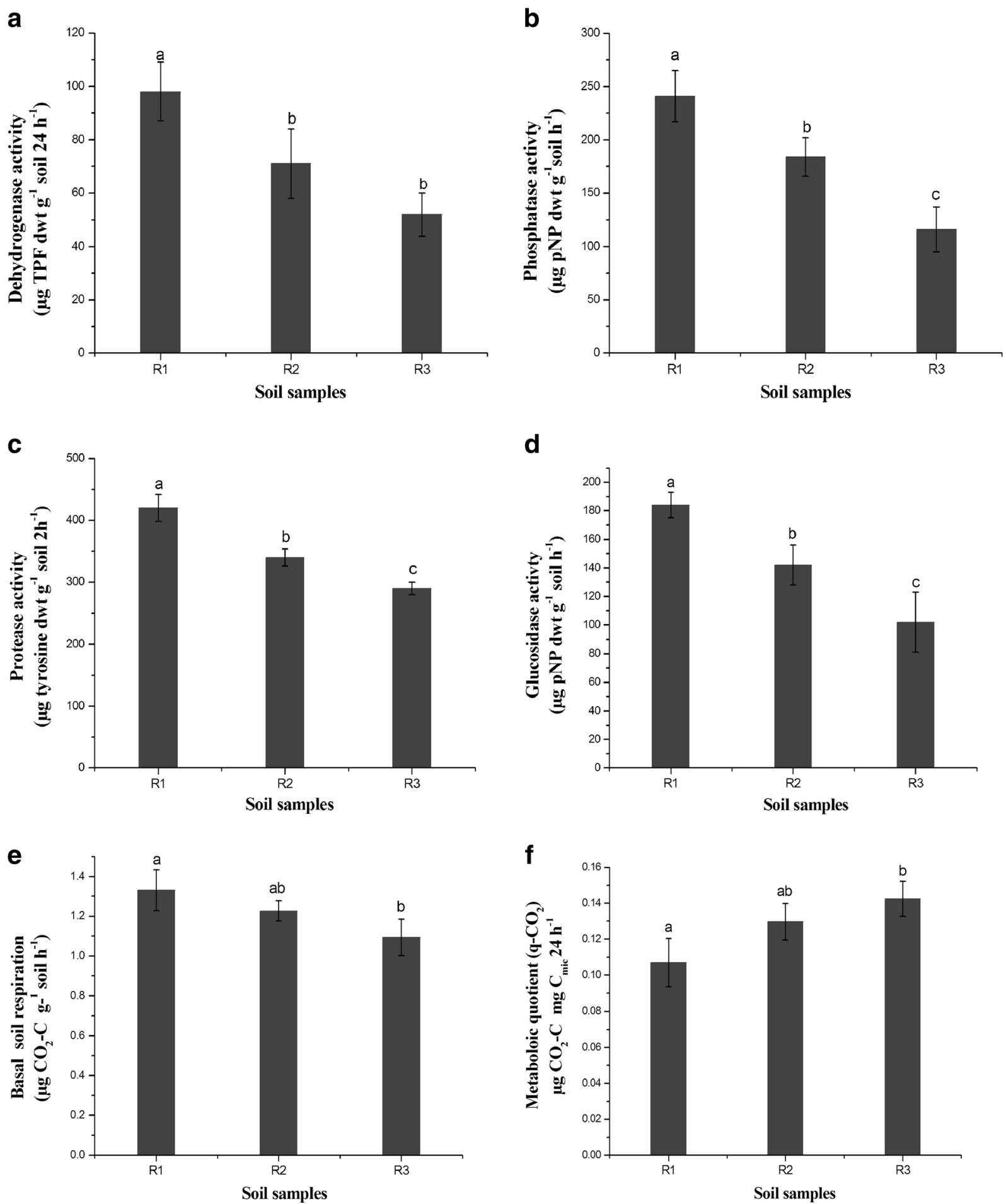

Fig. 2 Soil enzyme activities and basal soil respiration in three industrial waste effluent-contaminated soils. $R 1$, uncontaminated soil; $R 2$, moderately contaminated soil; $R 3$, highly contaminated soil. a Dehydrogenase activity (DHA); b phosphatase activity (PSA); c protease activity (PRA); d glucosidase activity (GSA);

e basal soil respiration (BSR); f soil metabolic quotient (q- $\left.\mathrm{CO}_{2}\right)$. Values are mean of three independent replicates $(n=3)$. Error bars represent standard deviation of mean $(n=3)$. Significant differences $(p<0.05$, LSD) between the means are indicated by different alphabets 
higher microbial enzyme activities were noticed in the control R1 soil. The microbial activities of polluted soils were expressed as a percentage of the control R1 soil. A significant decrease $(p<0.05$, LSD) in soil in situ microbial enzymes such as DHA, PSA, GSA, and PRA were found in long-term polluted soils (i.e., R2 and R3) (Fig. 2a-d). In R2 soil, enzymes DHA, PSA, GSA, and PRA were reduced to $27.5,23.6,22.8$, and $19.5 \%$, respectively, with reference to uncontaminated control R1 soil. Similarly, these values for R3 soil were reduced to be $46,51.8,44.5$, and $30.9 \%$, respectively. BSR differed among the soils tested. A significant reduction $(p<0.05$, LSD) in BSR was noticed in highly polluted soils (R3) (Fig. 2e). However, a significant increase in the metabolic quotient $\left(\mathrm{q}-\mathrm{CO}_{2}\right)$ values was associated with R3 soil (Fig. 2f).

Soil bacterial community analysis

The structure and diversity of bacterial community characterized by DGGE analysis of 16S rRNA gene were highly influenced by increasing contamination levels. A remarkable shift in the bacterial community along the contamination gradient was noticed in the DGGE profile (Fig. 3). Most of the DGGE bands in soil R1 were equally distributed along the denaturant gel gradient while bands in R2 and R3 soils were concentrated mainly in the middle of the gel gradient. Bands with the same mobility in the DGGE gel were marked with the same number. Bands S1, S2, and S9 were specific to R1 soil, and bands S3, S4, S6, S8, S12, S13, S17, S18, $\mathrm{S} 19, \mathrm{~S} 21, \mathrm{~S} 24$, and S26 were only present in R2 and R3 samples. Common DGGE bands (S7, S14, $\mathrm{S} 15, \mathrm{~S} 19$, and S20) were found in all the three sites, whereas band S15 was distinctly intensified along the contamination gradient (Fig. 3, Table 3). No significant $(p<0.05)$ difference in the diversity indices Shannon index $(H)$ and Evenness index $(E)$ was observed among the three sites. Relatively higher range-weighted richness $(R r)$ was observed in $\mathrm{R} 1$ (58.8) than in R2 (43.6) and R3 (44) soils. A total of 26 DGGE bands for bacterial 16S rRNA gene were excised (Fig. 3), reamplified, and sequenced for phylogenetic analysis (Fig. 4, Table 3). The sequences at $2 \%$ nucleotide cutoffs were used to construct phylogenetic trees with representative sequences retrieved from the GenBank database (www.ncbi.nlm.nih.gov). Major bacterial phyla in R1 soil were affiliated with

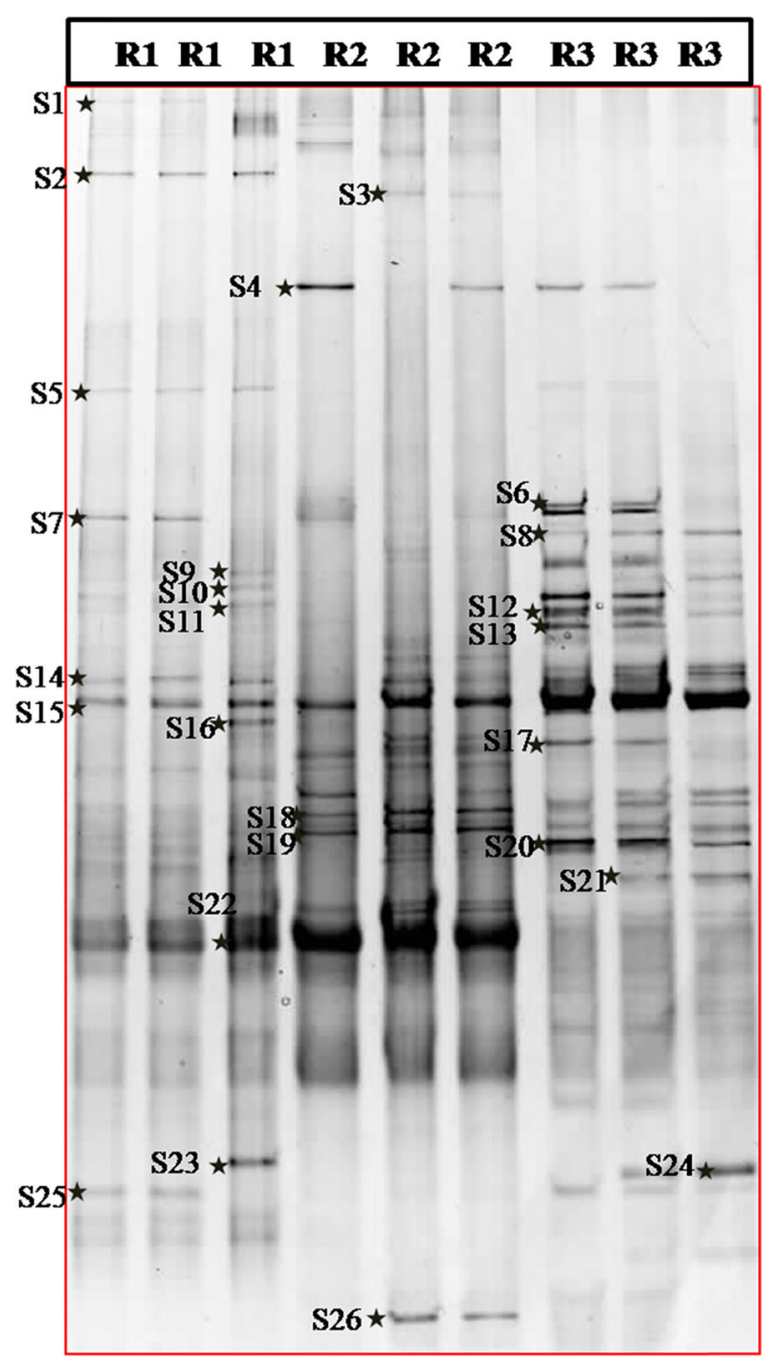

Fig. 3 Soil bacterial community structure as revealed by DGGE analysis of 16S rRNA gene in three industrial waste effluentcontaminated soils. Bands selected for cloning and sequencing analysis are shown with asterisk

Proteobacteria, Bacterioidetes, and Gemmatimonadetes, while phyla Proteobacteria, Actinobacteria, and Gemmatimonadetes were noticed in R2 soil. Bacterial phyla such as Actinobacteria, Verrucomicrobia, Proteobacteria, and Firmicutes were dominant in R3 soil (Table 3). Phylum Spirochaetes was found only in R2 soil (Fig. 4, Table 3). Phylum Acidobacteria was found in both R2 and R3 soils. Phyla Gemmatimonadetes, Proteobacteria, Actinobacteria, and Verrucomicrobia were common in all the three soils. When compared to control R1 soil, Alphaproteobacteria, Betaproteobacteria, Actinobacteria, and Firmicutes were dominated in polluted soils R2 and R3. 
Table 3 The dominant DGGE bands and their closest 16S rRNA gene match retrieved from three industrial waste effluent-contaminated soils

\begin{tabular}{|c|c|c|c|c|c|c|c|}
\hline \multirow[t]{2}{*}{$\begin{array}{l}\text { DGGE band } \\
\text { number }\end{array}$} & \multicolumn{3}{|c|}{$\begin{array}{l}\text { Presence and } \\
\text { absence of bands } \\
\text { in soil samples }\end{array}$} & \multirow{2}{*}{$\begin{array}{l}\text { GenBank } \\
\text { accession } \\
\text { number for } \\
\text { DGGE band }\end{array}$} & \multirow[t]{2}{*}{$\begin{array}{l}\text { Closest organism from the } \\
\text { GenBank (similarity \%) }\end{array}$} & \multirow[t]{2}{*}{$\begin{array}{l}\text { Accession number } \\
\text { of closet organism }\end{array}$} & \multirow[t]{2}{*}{ Bacterial phyla } \\
\hline & $\mathrm{R} 1$ & $\mathrm{R} 2$ & $\mathrm{R} 3$ & & & & \\
\hline S1 & + & - & - & JX504051 & Arcobacter sp. (99\%) & JX392996 & Epsilonproteobacteria \\
\hline $\mathrm{S} 2$ & + & - & - & JX504052 & Uncultured Bacteroidetes (92%) & HQ531691 & Bacterioidetes \\
\hline $\mathrm{S} 3$ & & + & & JX504053 & $\begin{array}{l}\text { Uncultured bacterium clone } \\
\quad(99 \%)\end{array}$ & FJ529958 & Bacterioidetes \\
\hline S4 & & + & + & JX504054 & $\begin{array}{l}\text { Uncultured Epsilonproteobacteria } \\
\quad(96 \%)\end{array}$ & AB293086 & Epsilonproteobacteria \\
\hline S5 & + & - & + or - & JX504055 & Rhodobacter sp. (97 \%) & JF681999 & Alphaproteobacteria \\
\hline S6 & - & - & + & JX504056 & Uncultured Geothrix sp. (99 \%) & AJ583203 & Acidobacteria \\
\hline S7 & + & + or - & + & JX504057 & Brevundimonas sp. (99 \%) & KF732706 & Alphaproteobacteria \\
\hline S8 & - & - & + & JX504058 & Pseudomonas sp. (98\%) & NR040992 & Gammaproteobacteria \\
\hline S9 & + & - & - & JX504059 & Marinobacter sp. (98\%) & AB513677 & Gammaproteobacteria \\
\hline S10 & + & - & - & JX504060 & Uncultured bacterium clone (99 \%) & JQ861418 & Verrucomicrobia \\
\hline S11 & + & - & + & JX504061 & Alcaligenes sp. (99\%) & KF500674 & Betaproteobacteria \\
\hline S12 & - & - & + & JX504062 & Bacillus sp. $(98 \%)$ & NR042894 & Firmicutes \\
\hline S13 & - & - & + & JX504063 & Exiguobacterium sp. (92 \%) & NR043204 & Firmicutes \\
\hline S14 & + & + & + & JX504064 & $\begin{array}{l}\text { Uncultured Gemmatimonadetes } \\
\text { sp. }(97 \%)\end{array}$ & FJ889270 & Gemmatimonadetes \\
\hline S15 & + & + & + & JX504065 & Uncultured bacterium clone (95\%) & EU133084 & Unclassified bacteria \\
\hline S16 & + & - & - & JX504066 & Uncultured bacterium clone (98 \%) & AF507430 & Unclassified bacteria \\
\hline S17 & - & + & + & JX504067 & $\begin{array}{l}\text { Uncultured Verrucomicrobia clone } \\
\quad(97 \%)\end{array}$ & AY922082 & Verrucomicrobia \\
\hline S18 & - & + & - & JX504068 & $\begin{array}{l}\text { Uncultured Acidobacteria clone } \\
\quad(95 \%)\end{array}$ & GQ120646 & Acidobacteria \\
\hline S19 & - & + & + & JX504069 & $\begin{array}{l}\text { Uncultured Gemmatimonadetes } \\
\text { sp. }(97 \%)\end{array}$ & DQ676286 & Gemmatimonadetes \\
\hline S20 & - & - & + & JX504070 & Uncultured bacterium clone (92\%) & EF494371 & Actinobacteria \\
\hline S21 & - & - & + & JX504071 & $\begin{array}{l}\text { Uncultured Actinobacterium clone } \\
\quad(98 \%)\end{array}$ & EU522663 & Actinobacteria \\
\hline S22 & + & + & - & JX504072 & $\begin{array}{l}\text { Uncultured Actinobacterium clone } \\
\quad(99 \%)\end{array}$ & EU522663 & Actinobacteria \\
\hline $\mathrm{S} 23$ & + & - & - & JX504073 & $\begin{array}{l}\text { Uncultured Actinobacterium clone } \\
\quad(96 \%)\end{array}$ & GQ120645 & Unclassified Actinobacteria \\
\hline S24 & - & - & + & JX504074 & Uncultured bacterium clone (98 \%) & EU133033 & Unclassified Actinobacteria \\
\hline S25 & + & - & + & JX504075 & Uncultured bacterium clone (96 \%) & EU133033 & Unclassified Actinobacteria \\
\hline S26 & - & + & - & JX504076 & $\begin{array}{l}\text { Uncultured Spirochaeta clone } \\
\quad(98 \%)\end{array}$ & AF349763 & Spirochaeta \\
\hline
\end{tabular}

Relation between soil chemical characteristics and soil microbial parameters

The factors significantly affected the bacterial community were extracted by principal components analysis (PCA) and the ordination biplot of the PCA loadings is presented in Fig. 5. Principle components PC1 and PC2 together accounting for $81.6 \%$ of the total variance observed in the data. PCA revealed that much of the variance in soil chemical properties between the soils was associated with heavy metals and PAHs. The ordination biplot showed an apparent deleterious effect of heavy metals and PAHs on soil microbial parameters. Microbial diversity indices such as $R r$ correlated well 


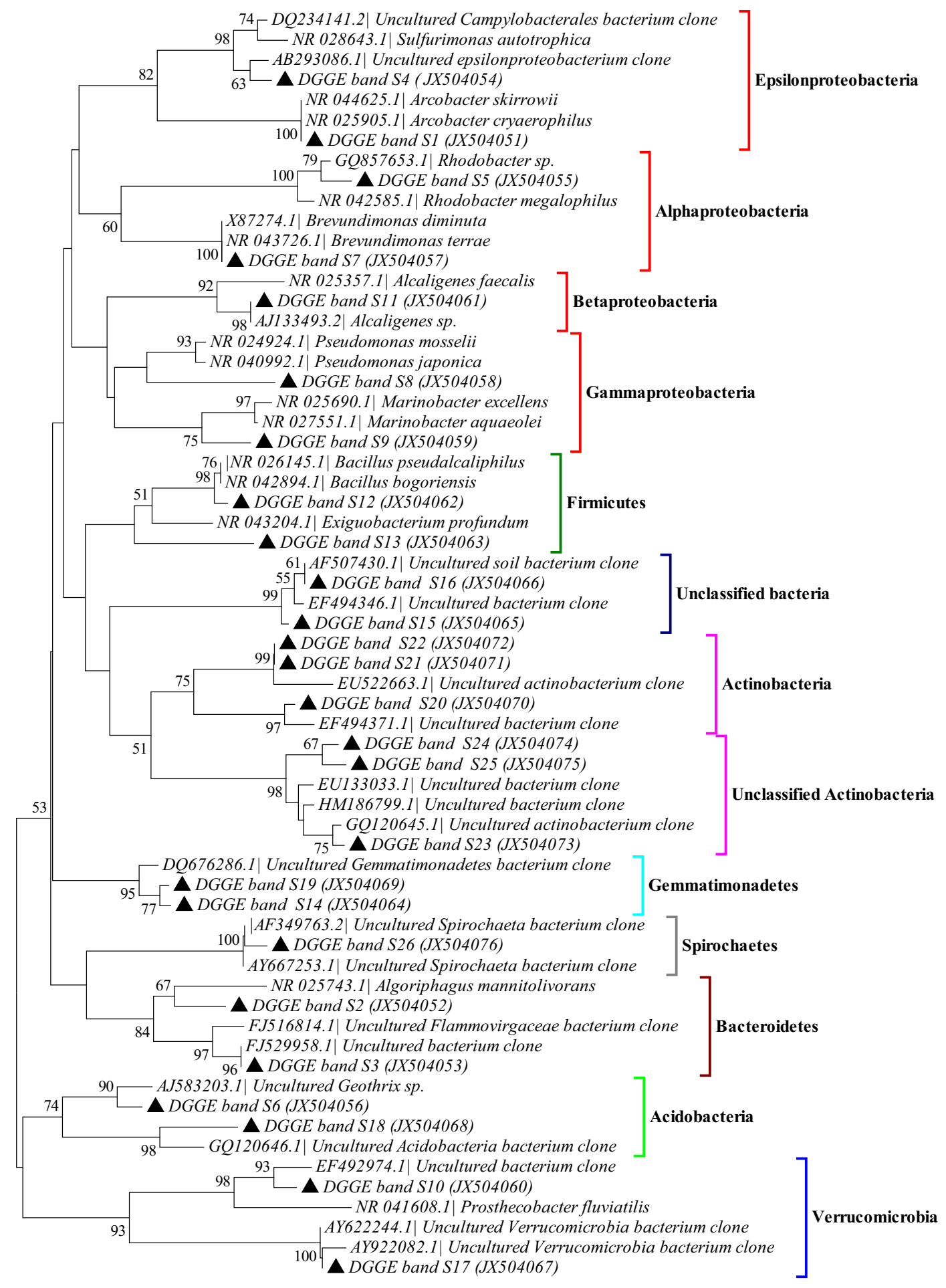

\subsection{5}

Fig. 4 Neighbor joining phylogenetic tree of bacterial 16S rRNA gene sequences derived from the dominant DGGE bands. The sequences retrieved in this study are indicated in bold including the clone name, and respective GenBank accession number (in parentheses). Bootstrap values $(>50 \%)$ are indicated at branch points. The scale bar represents $5 \%$ sequence divergence. Representative bacterial phyla under which the sequences belong are also shown 
Fig. 5 Coordination biplots of principle component analysis (PCA) with soil chemical variables and microbial parameters. Correlations between chemical variables and PCA axes are represented by the length and angle of lines (environmental factor vectors). Effect of IWE on soil bacterial community was shown with sampling sites (represented with red circles [for $\mathrm{R} 1]$, green triangles [for R2], and blue squares [for R3]. The length of the arrow indicates the relative variance explained by that factor. The replicates for each soil were indicated with numbers, such as treatment R1: R1.1, R1.2, and R1.3

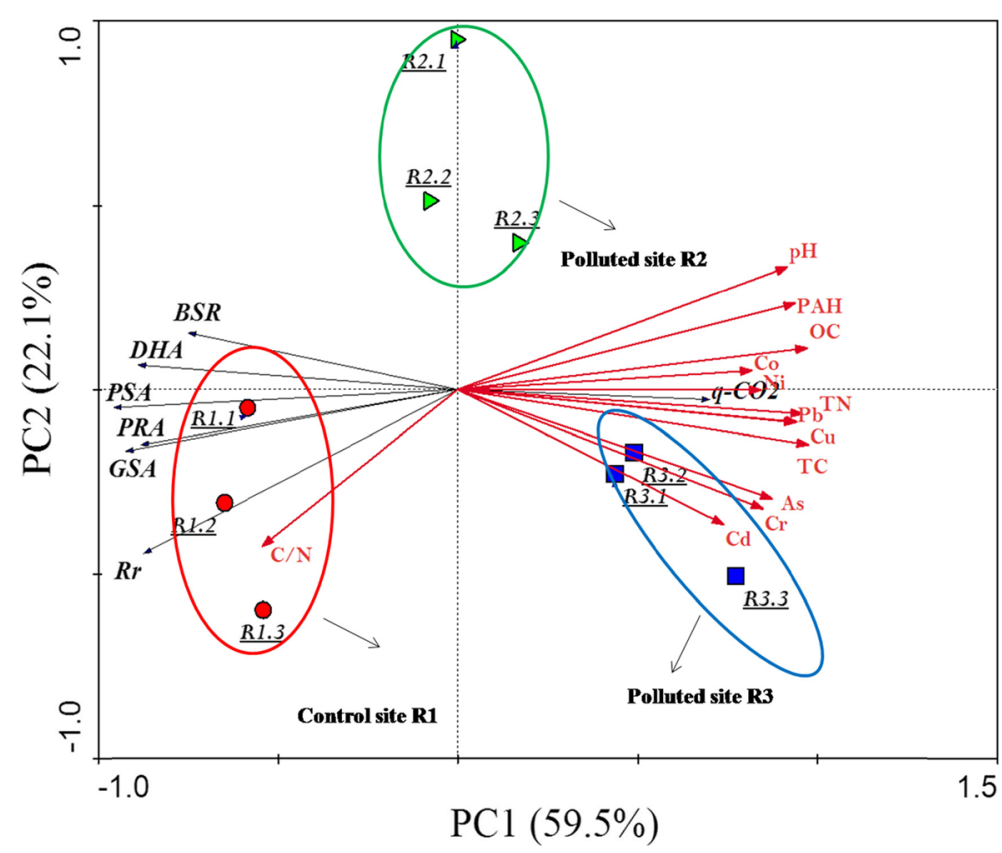

with soil enzyme activities (Fig. 5). All the microbial activity parameters were positively correlated with each other. Strong positive correlation between $\mathrm{q}-\mathrm{CO}_{2}$ and soil heavy metals was noticed (Fig. 5). The microbial diversity index as indicated by $R r$ negatively correlated with soil pollution.

\section{Discussion}

Understanding the environmental as well as anthropogenic influences on microbial activity and diversity is the key to predict changes in the nutrient cycling of semiarid soils. Soil microbial enzymes play a key role in the decomposition of organic residues and are considered fundamentally as good indicators for soil quality (Gil-Sotres et al. 2005). In order to evaluate the fluxes of elements in highly contaminated soils, hydrolytic enzymes such as GSA, PRA, and PSA involved in C, N and $\mathrm{P}$ cycles, respectively, were determined in the present study. It was found that the activities of these enzymes were significantly decreased in the contaminated soils R2 and R3 even if the contaminated soil contain significantly higher nutrients such as OM, TOC, TC, $\mathrm{TN}$, and $\mathrm{NH}_{4}{ }^{+} / \mathrm{NO}_{3}{ }^{-}$than uncontaminated soil $\mathrm{R}$. It could be inferred that microbial-mediated $\mathrm{C}, \mathrm{N}$, and $\mathrm{P}$ cycles were considerably affected by the long-term IWE contamination and thus soil health may be endangered.
PCA analysis further showed the overwhelming deleterious effect of heavy metals and PAHs on soil microbial parameters. It has been reported that DHA is associated with living cells, linked with microbial oxidation and reduction processes and is the principal agent in the degradation of soil organic matter (Tabatabai 1994). A remarkable high DHA activity found in R1 (reference soil) was in general agreement with high microbial respiration activity, indicating that organic matter decomposition is much active in uncontaminated soils. It can be inferred that soil in situ enzymes, particularly PSA and GSA, could be considered as bio-indicators to evaluate IWE pollution in semiarid tropic soils as enzymatic activities are reliable bio-indicators to emphasize natural and toxicological effects of various pollutants on soil microbial quality (Cycoń and Piotrowska-Seget 2015).

The oxidation of organic matter to $\mathrm{CO}_{2}$ by heterotrophic microorganisms is a vital process in the carbon cycle of terrestrial ecosystems. In previous studies, Winding et al. (2005) reported that soil respiration is a good indicator to distinguish different soil types and land use management. Khan et al. (2007) observed that soil respiration significantly reduced by organic and inorganic pollutants. In the present study, lower BSR but higher metabolic quotient $\left(\mathrm{q}-\mathrm{CO}_{2}\right)$ values observed in $\mathrm{R} 3$ soil was in agreement with the above observations, which indicated pollution induced stress 
on soil microbial populations. Similar results were also observed in heavy metals-polluted soils (GilSotres et al. 2005; Zhang et al. 2010a). Taken together, BSR and enzyme activities were higher in R1 but lower in R2 and R3 soils indicating that the microbes have greater potential in SOM decomposition and carbon flow to the atmosphere (Schlesinger and Andrews 2000) in an unpolluted soil, and soil contamination caused negative impacts on the soil microbiological characteristics. While some studies observed a certain increase of microbial activities in contaminated soils (Fließbach et al. 1994). This discrepancy was likely due to differences in contamination level and microbial community structure which varied with soils.

Molecular techniques based on universal bacterial 16S rRNA gene allow researchers to decipher bacterial communities compared to cultivation-based techniques. DGGE profiling of soil community DNA fragments enables to monitor the spatial and temporal changes in microbial community structure and provides a comparative picture of the dominant microbial species of polluted soils (Qu et al. 2011; Zhang et al. 2014). Phylogenetic analysis of 16S rRNA gene clearly indicated the selection in eubacterial community structure with response to IWE pollution.

In this study, the profiles of 16S rRNA gene-based DGGE and sequencing analysis of selected DGGE bands clearly indicated that bacterial community shifted obviously and some specific bacterial populations were selected with increasing contamination levels (Fig. 3). In pristine R1 soil, a high percentage of bacteria belonging to the phyla Proteobacteria and Actinobacteria were found. In addition, Verrucomicrobia, Bacteroides, and Gemmatomonoadetes phyla were also detected. These bacterial phyla were common in semiarid pristine soils as described earlier (Hendrickx et al. 2005). Whereas in contaminated R2 and R3 soils, phyla Firmicutes, Actinobacteria, and Acidobacteria represented by bands S12, S13, S6, S20, S21, S22, and S24 were found to be the abundant bacterial lineages pointing their endurance and adaptability to pollution stresses. In this study, many DGGE bands could not be assigned to any bacterial phylum and remained to be unclassified, suggesting hitherto unidentified populations, and immense unexplored microbial diversity. In addition, bands S2, S13, $\mathrm{S} 15$, and S20 showed less similarity $(<95 \%)$ to the closest organism from the GenBank indicating novel bacterial populations distributed in these soils which are less known and may represent the novel species. The abundance of class Betaproteobacteria and Gammaproteobacteria (Pseudomonas sp.) were detected in R3. These phyla are frequently observed in soils contaminated with persistent organic pollutants, hydrocarbons, and heavy metals in many previous studies (Hendrickx et al. 2005; Nakatsu et al. 2005; Janssen 2006; Popp et al. 2006; Bordenave et al. 2007; Vivas et al. 2008; Liao et al. 2010; Zhang et al. 2010a, b). The phylogenetic classification of many bacteria isolates from these contamination soils are consistent with in situ analyses of bacterial community structure in present and other studies (Gremion et al. 2003; Keshri et al. 2014). The Actinomycetales have been reported to be important in metal-impacted soils (Nakatsu et al. 2005). The populations represented by S2, S22, etc. disappeared/absented in highly contaminated soil indicating their sensitivity to contamination. Hence, we propose here that change in the abundance of specific bacteria populations represent the biological indicative markers for semiarid soil contamination by a mixed bag of pollutants. These bacteria groups may have a great potential for the bioremediation of toxic chemicals. Indigenous microorganisms as potential bioremediators for environments contaminated with heavy metals were reported in the earlier studies (Colin et al. 2012; Keshri et al. 2014).

\section{Conclusions}

Long-term contamination of the semiarid soils by industrial waste caused distinct bacterial community shift and possibly selected specific populations with certain resistant ability for polluted soil. We propose that soil enzyme activities and presence/absence of specific bacterial phyla as possible relevant biological markers for assessing soil quality under long-term IWE pollution. Although the negative impact of IWE pollution on soil microbial activity is observed, it becomes very difficult to distinguish relative toxicity of specific pollutants as the present soils are exposed to a mixed contamination of various metals and organic pollutants. Laboratory microcosm studies with specific pollutants and interpreting their effect would be useful for better understanding the critical contaminants of IWE and their impact on soil microbial community. 
Acknowledgments This work was funded by the Chinese Academy of Sciences (CAS), Beijing, China, and Academy of Sciences for the Developing World (TWAS), Trieste, Italy, under the scheme "TWAS-CAS fellowship programme for postgraduate research" to GS for the year 2010. This work was jointly supported by the National Natural Science Foundation of China (Grant No. 41322007) and the Foundation for Innovative Research Groups of the National Natural Science Foundation of China (Grant No. 51221892).

\section{References}

Alef, K., \& Nannipieri, P. (1995). Methods in applied soil microbiology and biochemistry. London: Academic Press.

Bishnoi, K., Sain, U., Kumar, R., Singh, R., \& Bishnoi, N. R. (2009). Distribution and biodegradation of polycyclic aromatic hydrocarbons in contaminated sites of Hisar (India). Indian Journal of Experimental Biology, 47, 210-217.

Bordenave, S., Goñi-Urriza, M. S., Caumette, P., \& Duran, R. (2007). Effects of heavy fuel oil on the bacterial community structure of a pristine microbial mat. Applied and Environmental Microbiology, 73, 6089-6097.

Colin, V. L., Villegas, L. B., \& Abate, C. M. (2012). Indigenous microorganisms as potential bioremediators for environments contaminated with heavy metals. International Biodeterioration and Biodegradation, 69, $28-37$.

Cycoń, M., \& Piotrowska-Seget, Z. (2015). Biochemical and microbial soil functioning after application of the insecticide imidacloprid. Journal of Environmental Sciences, 27, 147-158.

Fließbach, A., Martens, R., \& Reber, H. H. (1994). Soil microbial biomass and microbial activity in soil treated with heavy metal contaminated biosolids. Soil Biology and Biochemistry, 26, 1201-1205.

Gil-Sotres, F., Trasar-Cepeda, C., Leirós, M. C., \& Seoane, S. (2005). Different approaches to evaluating soil quality using biochemical properties. Soil Biology and Biochemistry, 37, 877-887.

Gremion, F., Chatzinotas, A., \& Harms, H. (2003). Comparative $16 \mathrm{~S}$ rDNA and 16S rRNA sequence analysis indicates that Actinobacteria might be a dominant part of the metabolically active bacteria in heavy metal contaminated bulk and rhizosphere soil. Environmental Microbiology, 5, 896-907.

Hendrickx, B., Dejonghe, W., Boënne, W., Brennerova, M., Cernik, M., Lederer, T., et al. (2005). Dynamics of an oligotrophic bacterial aquifer community during contact with a groundwater plume contaminated with benzene, toluene, ethylbenzene and xylenes: an in situ mesocosm study. Applied and Environmental Microbiology, 71, 3815-3825.

Igbinosa, E. O. (2015). Effect of cassava mill effluent on biological activity of soil microbial community. Environmental Monitoring and Assessment, 187, 418. doi:10.1007/s10661015-4651-y.

Janssen, P. H. (2006). Identifying the dominant soil bacterial taxa in libraries of $16 \mathrm{~S}$ rRNA and 16S rRNA genes. Applied and Environmental Microbiology, 72, 1719-1728.
Jones, S. E., \& Lennon, J. T. (2010). Dormancy contributes to the maintenance of microbial diversity. Proceedings of the National Academy of Sciences of the United States of America, 107, 5881-5886.

Keshri, J., Mankazana, B. B., \& Momba, M. N. (2014). Profile of bacterial communities in South African mine-water samples using Illumina next-generation sequencing platform. Applied Microbiology and Biotechnology, 99, 3233-3242.

Khan, S., Cao, Q., Hesham, A. E. L., Xia, Y., \& He, J. Z. (2007). Soil enzymatic activities and microbial community structure with different application rates of $\mathrm{Cd}$ and $\mathrm{Pb}$. Journal of Environmental Sciences, 19, 834-840.

Labunska, I., Stephenson, A., Brigden, K., Santillo, D., Stringer, R., Johnston, P.A., \& Ashton, J. M. (1999). Organic and heavy metal contaminants in samples taken at three industrial estates in Gujarat, India. Green Peace Research Laboratories, Netherlands. Technical Note 05/99. (http://www.greenpeace. org/international/Global/international/planet2/report/1999/11/ toxichotspots-a-greenpeace.pdf/).

Liao, M., Xie, X., Ma, A., \& Peng, Y. (2010). Different influences of cadmium on soil microbial activity and structure with Chinese cabbage cultivated and non-cultivated. Journal of Soils and Sediments, 10, 818-826.

Nakatsu, C. H., Carmosini, N., Baldwin, B., Kourtev, P., Konopka, A., Nakatsu, C. H., et al. (2005). Soil microbial community responses to additions of organic carbon substrates and heavy metals $(\mathrm{Pb}$ and $\mathrm{Cr})$. Applied and Environmental Microbiology, 71, 7679-7689.

Popp, N., Schlömann, M., \& Mau, M. (2006). Bacterial diversity in the active stage of a bioremediation system for mineral oil hydrocarbon-contaminated soils. Microbiology, 152, 3291-3304.

Qu, J., Ren, G., Chen, B., Fan, J., \& Yong, E. (2011). Effects of lead and zinc mining contamination on bacterial community diversity and enzyme activities of vicinal cropland. Environmental Monitoring and Assessment, 182, 597-606.

Schlesinger, W. H., \& Andrews, J. A. (2000). Soil respiration and global carbon cycle. Biogeochemistry, 48, 7-20.

Sheik, C. S., Mitchell, T. W., Rizvi, F. Z., Rehman, Y., Faisal, M., et al. (2012). Exposure of soil microbial communities to chromium and arsenic alters their diversity and structure. PloS One, 7, e40059.

Shen, J. P., Zhang, L. M., Zhu, Y. G., Zhang, J. B., \& He, J. Z. (2008). Abundance and composition of ammonia-oxidizing bacteria and ammonia oxidizing archaea communities of an alkaline sandy loam. Environmental Microbiology, 10, 1601-1611.

Subrahmanyam, G., Archana, G., \& Chamyal, L. S. (2011). Microbial activity and diversity in the late Pleistocene palaeosols of alluvial Mahi River basin, Gujarat, western India. Current Science India, 101, 202-209.

Subrahmanyam, G., Hu, H. W., Zheng, Y. M., Archana, G., He, J. Z., \& Liu, Y. R. (2014a). Response of ammonia oxidizing microbes to the stresses of arsenic and copper in two acidic alfisols. Applied Soil Ecology, 77, 59-67.

Subrahmanyam, G., Khonde, N., Maurya, D. M., Chamyal, L. S., \& Archana, G. (2014b). Microbial activity and culturable bacterial diversity in the sediments of Great Rann of Kutch, a unique ecosystem, Western India. Pedosphere, 24, 45-55.

Subrahmanyam, G., Shen, J. P., Liu, Y. R., Archana, G., \& He, J. Z. (2014c). Response of ammonia-oxidizing archaea and 
bacteria to long-term industrial effluent-polluted soils, Gujarat, Western India. Environmental Monitoring and Assessment, 186, 4037-4050.

Tabatabai, M. A. (1994). Soil enzymes. In R.W. Weaver et al. (Eds.), Methods of soil analysis: microbiological and biochemical properties. Part 2. SSSA Book Ser. 5. Soil Sci Soc Am. Madison, pp. 775-834.

Thavamani, P., Malik, S., Beer, M., Megharaj, M., \& Naidu, R. (2012). Microbial activity and diversity in long-term mixed contaminated soils with respect to polyaromatic hydrocarbons and heavy metals. Journal of Environmental Management, 99, 10-17.

Tian, Y., Liu, H. J., Zheng, T. L., Kwon, K. K., Kim, S. J., \& Yan, C. L. (2008). PAHs contamination and bacterial communities in mangrove surface sediments of the Jiulong River Estuary, China. Marine Pollution Bulletin, 57, 707-715.

U.S. EPA (1996) Method 3540C, Soxhlet extraction. <http://www. epa.gov/osw/hazard/testmethods/sw846/pdfs/3540c.pdf (14.03.14).

Vance, E. D., Brookes, P. C., \& Jenkinson, D. S. (1987). An extraction method for measuring microbial biomass C. Soil Biology and Biochemistry, 19, 703-707.

Vivas, A., Moreno, B., del Val, C., Macci, C., Masciandaro, G., \& Benitez, E. (2008). Metabolic and bacterial diversity in soils historically contaminated by heavy metals and hydrocarbons. Journal of Environmental Monitoring, 10, 1287-1296.
Wang, Y. P., Shi, J. Y., Lin, Q., Chen, X. C., \& Chen, Y. X. (2007). Heavy metal availability and impact on activity of soil microorganisms along a $\mathrm{Cu} / \mathrm{Zn}$ contamination gradient. Journal of Environmental Sciences, 19, 848-853.

Winding, A., Hund-Rinke, K., \& Rutgers, M. (2005). The use of microorganisms in ecological soil classification and assessment concepts. Ecotoxicology and Environmental Safety, 62, 230-248.

Yu, Z., \& Morrison, M. (2004). Comparisons of different hypervariable regions of rrs genes for use in fingerprinting of microbial communities by PCR-denaturing gradient gel electrophoresis. Applied and Environmental Microbiology, 70, 4800-4806.

Zhang, F. P., Li, C. F., Tong, L. G., Yue, L. X., Li, P., Ciren, Y. J., \& Cao, C. G. (2010a). Response of microbial characteristics to heavy metal pollution of mining soils in central Tibet, China. Applied Soil Ecology, 45, 144-151.

Zhang, W., Wang, H., Zhang, R., Yu, X. Z., Qian, P. Y., \& Wong, M. H. (2010b). Bacterial communities in PAH contaminated soils at an electronic-waste processing center in China. Ecotoxicology, 19, 96-104.

Zhang, Q., Zhu, L., Wang, J., Xie, H., Wang, J., Wang, F., \& Sun, F. (2014). Effects of fomesafen on soil enzyme activity, microbial population, and bacterial community composition. Environmental Monitoring and Assessment, 186, 2801-2812. 